\title{
MODIFICACIONES DE ALGUNOS ASPECTOS DEL FACTOR CERVICAL MEDIANTE EL EMPLEO DE LA MEDROXIPROGESTERONA DE DEPOSITO. INFORME PRELIMINAR
}

\author{
Dr. Ricardo Rueda González*
}

\section{Introducción}

El compuesto 6 alpha-etyl-hidroxiprogesterona 0 acetato de medroxiprogesterona, es un potente agente progestacional que puede ser administrado por vía oral o parenteral, y que por consiguiente se puede catalogar como un agente contraceptivo de elevada efectividad cuando se suministra en dosis adecuadas.

Los trabajos de varios investigadores (1-2), aseveran el hecho de que se trata de un potente inhibidor de las gonadotropinas y que cuando es inyectado, gracias a su lenta absorción, es capaz de mantener este efecto por períodos prolongados que varían de acuerdo a su concentración.

Otro de los efectos ya descritos de estos compuestos (3), y en que juega un papel preponderante la medroxiprogesterona como agente contraceptivo, es su acción sobre algunos aspectos del factor cervical, los cuales por sí solos pueden constituir una barrera para la fecundación.

Para el estudio de nuestras pacientes empleamos la dosis de $150 \mathrm{mg}$. sin adición alguna de estrógenos con el fin de no desvirtuar las apreciaciones encaminadas a la observación de la acción del gestágeno solo sobre el factor cervical.

Por otra parte aceptamos, que la Medroxiprogesterona de depósito en dosis de 150 mgs. administrada por la vía intramuscular, ejerce una acción contraceptiva de noventa días de duración (4), y en base a ello dirigimos nuestra investigación con miras al estudio de las variaciones ejercidas por la hormona durante este período de tiempo sobre la dificultad creada a nivel del cuello uterino para la concepción.

Consideramos al igual que muchos autores (5-6-7), que el factor cervical desde el punto de vista funcional puede estudiarse en forma racional y con bastante aproximación, mediante tres pruebas fundamentales:

a) Estudios cristalográficos del moco cervical.

b) Estudio de la filancia o capacidad de dejarse estirar en forma de hilo y denominada por algunas escuelas como fenómeno del "Spinnbarkeit".

* Profesor Asistente Ginecología. Fac. Medicina Universidad Nacional de Colombia. Del Servicio de Ginecología Hospital Militar Central. 
c) Pruebas postcoito como la de Sims-Huhner o similares.

En términos generales se acepta también que la acción progestacional sea natural 0 inducida mediante el empleo de gestágenos, modifica las pruebas mencionadas en la siguiente forma: (8)

1. Desaparición de la cristalización en forma de helecho del moco cervical.

2. Disminución hasta desaparición de la filancia del mismo, y

3. Disminución y dificultad para la espermomigración, claramente detectable en los test post-coito.

En base a los hechos anotados anteriormente, encaminamos nuestro estudio a puntualizar las variaciones que en estos tres exámenes se pudieran presentar en las pacientes sometidas a la acción de la Medroxiprogesterona de Depósito en una concentración de 150 mgs. aplicados en una sola inyección y durante 90 días. Dicha inyección se practicó siempre el primer día del ciclo y nunca en el puerperio.

No está por demás anotar la dificultad para motivar las pacientes hacia un programa de anticoncepción mediante el uso de gestágenos de depósito, ya que se trata de una forma relativamente nueva entre nosotros, y más aún, el dejarse practicar el estudio del factor cervical con la frecuencia que requería nuestro propósito.

No encontramos dificultades mayores para el estudio cristalográfico y de filancia del moco cervical distintas, a las de no poderlos practicar en fechas exactas, debido al sangrado irregular transhormonal frecuente en este tipo de terapia. En cambio, para el test post-coito, además de la ya anotada, tropezamos con serias dificultades inherentes a las indicaciones e instrucciones mismas para realizarlos correctamente y siguiendo las normas clásicas ya establecidas.

Por estas razones nuestra casuística para la presente oportunidad no es tan numerosa como quisiéramos, pero en todo caso ella nos puede dar una idea de las modificaciones que se operan sobre uno de los mecanismos de acción como contraceptivo del gestágeno en estudio.

\section{Material y Métodos}

Se motivó un grupo de pacientes en forma individual hacia la anticoncepción con gestágenos de depósito, haciéndoles hinchpié sobre la ventaja de su sencillez y alta efectividad.

De este grupo se seleccionaron 13 (trece) pacientes que se sometieron previamente a estudio de infertilidad especialmente dirigido hacia ovulación y factor cervical. Ninguna de ellas se hallaba en puerperio inmediato ni había ejercido forma alguna de anticoncepción. Dos fueron rechazadas de la investigación, una por presentar franca hostilidad cervical y otra por anovulación. Los espermogramas de los esposos de las 11 pacientes finalistas fueron clasificados como fértiles.

Concluida esta etapa preliminar, y después de inyectar la Medroxiprogesterona en la dosis ya denominada, se procedió a practicar periódicamente el estudio cervical con las tres pruebas que hemos considerado como aceptables, en la siguiente forma:

1. Spinnbarkeit y cristalización de moco cervical una vez en la semana, con un total de 12 pruebas de esta naturaleza por cada una de las pacientes. 
2. Prueba de Sims-Huhner. Ante las dificultades ya anotadas se practicó una prueba cada dos semanas y en fechas variables para lograr evitar su práctica en las ocasiones en que se presentaba el sangrado irregular. En total seis pruebas post-coito para cada paciente en el curso de noventa días.

\section{Nomenclatura}

Interpretamos nuestros resultados con la siguiente nomenclatura que seguimos siempre en los estudios de esta naturaleza y que consideramos aceptable:

a) Para el Spinnbarkeit.

Pequeño: 1 a $3 \mathrm{cms}$. de longitud del filamento.

Mediano: 4 a $10 \mathrm{cms}$.

Largo: 11 a $15 \mathrm{cms}$. O más.

b) Para el estudio cristalográfico:

Cristalización negativa (-).

Cristalización positiva $(+) ;(++)$; $(+++)$; según la intensidad y abundancia de las imágenes en helecho.

c) Para la prueba de Sims-Huhner:

Negativa: 0 Espermatozoides en la muestra cervical.

Pobre: $X$ Número de espermatozoides muertos en la muestra cervical.

Regular: 1 a 5 espermatozoides móviles por campo en la muestra cervical.

Buena: 6 a 20 espermatozoides por campo en la muestra cervical (móviles).

Excelente: Más de 20 espermatozoides móviles por campo en la muestra cervical.

\section{Resultados}

Con muy pequeñas variaciones, los resultados obtenidos con los estudios descritos anteriormente pudimos establecer lo siguiente:

1. CRISTALIZACION. La cristalización en forma de helechos se mantiene positiva +++ durante la primera semana que sigue a la aplicación de la droga, para hacerse totalmente negativa en la segunda semana y permanecer así hasta la duodécima en la que ocasionalmente pueden observarse imágenes en helecho clasificables como de + .

En las pacientes en que se practicó este estudio ocasionalmente poco antes o muy poco después de un sangrado irregular, encontramos imágenes en helecho clasificables como de + y hasta de ++ .

2. SPINNBARKEIT. La filancia del moco cervical disminuyó verticalmente desde el primer examen, observándose ya desde la primera semana un filamento pequeño ( 1 a $3 \mathrm{cms}$.) que permaneció inalterado hasta el final del estudio.

3. PRUEBA DE SIMS-HUHNER. Quizás las pruebas post-coito fueron las que observamos descender en forma más gradual. Como ya lo anotamos se practicaron con intervalos aproximados de dos semanas y por consiguiente con un total de seis.

En base a la nomenclatura por nosotros empleada, logramos establecer la siguiente curva:

1. Quincena: Buena.

2. Quincena: Pobre.

3: Quincena: Pobre.

4: Quincena: Pobre.

5. Quincena: Negativa.

6. Quincena: Negativa. 
También se presentaron algunos cambios en los resultados cuando la prueba era practicada poco antes 0 después de un sangrado irregular, observando una regresión en favor en la espermopenetración.

\section{Resumen y Conclusiones}

Se someten 11 mujeres fértiles a la acción de la Medroxiprogesteronaacetato de depósito y en dosis de 150 mgs. con fines contraceptivos, y cuyos maridos se clasificaron también como fértiles.

A todas ellas se estudia el factor cervical desde el punto de vista funcional.

Las pruebas empleadas en el estudio arrojan resultados de una típica acción progestacional, y en ellas se pudo evidenciar como los mecanismos anticonceptivos de la Medroxiprogesterona de Depósito se instalan en forma rápida y se sostienen durante las doce semanas previstas.

Es posible que las variaciones de la concentración de la hormona en el organismo responsables del sangrado transhormonal, produzcan una ligera regresión en la negatividad de las pruebas, sin que en ningún momento se lograran clasificar como satisfactorias.

La hostilidad cervical traducida en pruebas post-coito "pobres" y "negativas", y en la notoria disminución de la filancia del moco, nos indica que la barrera cervical a la espermopenetración es calificable de excelente.

La desaparición do los helechos en el moco, y su ocasional aparición durante la terapia, nos confirma la potente acción progestacional de la droga y su gran poder de acción sóbre el mecanismo endocrino de la ovulostasis.

\section{BIBLIOGRAFIA}

1 MISHEL R. DANIL; GOOG, ROBERT C.; MEYER, DEAN: "Study of long acting inyectable Medroxiprogesterone acetate for contraceptiv use". Presented at AA. PP. miting. Atlanta. Ga. USA. April, 1967. Reprint.

2 ZAÑARTU, JUAN; RICE WRAY, EDRIS GOLDZEIER, JOSEPH: "Fertility Control with long acting inyectable steroids". A preliminar report. Gynecology - Obstetrics. Vol. 28 No 4 October 1966.

3 ZAÑARTU, JNAN: "Efect of sintetic oral gestagens on cervical mucus and sperm-penetration". Intern. J. Fer. 1: 225. 1963.

4 TYLER, EDWARD: "The use of a long-acting progestogen by injection for control of conception". Presented a the meeting of the IPPF. Santiago - Chile. Abril 9-15 1967. Reprint.

5 ISRAEL, S. LEON: "Diagnosis and tratment of menstrual disorders and sterility". Fourth Edition. Paul B. Hoeber, Inc. New York, 1959.

6 PARADELO, CARLOS A.; MAZZEDRA, JOSE MARIA; BETTINOTTI, ALBERTO: "Esterilidad por factor cervical". Edit. Vergara. Buenos Aires 1953.

7 TYLER, EDWARD: "Esterilidad. Estudio y tratamiento de la pareja estéril". Edit. Panamericana. Buenos Aires. 1963.

8 HALLER, JURGEN: "Ovuolstasis hormonal". Edit. Alhambra S. A. Buenos Aires. 1966. 